\title{
¿En un futuro podremos decir que la Reforma de Salud en el Perú funcionó?
}

In the future might we say that the Health Reform actually worked in Peru?

\author{
Giancarlo F. Castillo-Tarrillo,2, Georgette Vetanzo-Sánchez ${ }^{1,2}$ \\ Estudiante de Medicina Humana de la Universidad Nacional Mayor de San Marcos. \\ ${ }^{2}$ Sociedad Científica de San Fernando.
}

An Fac med. 2015;76(3):291-2 / http://dx.doi.org/10.15381/anales.v76i3.11243

\section{SR. EDITOR:}

Las reformas de salud tienen el objetivo de universalizar los recursos y servicios, buscando la equidad para una mejor calidad de vida en la población sin que exista impedimento alguno. Asistimos a un simposio sobre las reformas de salud en Latinoamérica, organizado en el contexto del V Congreso de la Red Bioética UNESCO, donde se dio a conocer las diferentes visiones de la reforma de salud aplicada en diferentes países como Colombia, Brasil, Ecuador y República Dominicana. Lamentablemente, la reforma aplicada en el siglo XX en dichos países ha resultado un fracaso; por lo que nos hicimos una pregunta, ¿funcionará en el Perú?, sabiendo que cuando seamos médicos serviremos de acuerdo con la Reforma, si es que esta se llegase a concretar.

En la organización de un sistema sanitario, lo ideal sería que el paciente acuda desde la comunidad al hospital pasando por la atención primaria (AP), para que la respuesta médica sea apropiada a las necesidades ${ }^{(1)}$. En el caso del Perú, no existe ello; las personas acuden a los hospitales generando una mayor demanda y, como consecuencia, el sistema de salud no es el adecuado; por tanto, una de las medidas planteadas por la reforma sería establecer la atención primaria.

La atención primaria tiene la finalidad de ser un filtro con los 'médicos de cabecera' antes de llegar a los hospitales, de tal forma que exista una mayor atención de la población, satisfaciendo sus necesidades, promoviendo la salud y previniendo enfermedades; así se logrará la disminución de la morbilidad y mortalidad. Es decir, la AP hace que cambie el paradigma de diagnosticar enfermedades hacia una atención personal, dirigida al individuo. Este modelo no ha tenido el éxito en los países en desarrollo como sí lo tuvo en países europeos, ya que en los primeros se tiene una visión errónea. Se la entiende como una atención básica y primitiva con profesionales de baja consideración social, e incluso los mismos médicos generales desmeritan su labor; por lo que se precisa una política sanitaria y profesional para cambiar dicha visión ${ }^{(2)}$.

Por otro lado, en el Perú no existen muchos centros especializados públicos, además de no contar con los recursos necesarios para crear otros. La reforma buscaría privatizar los centros existentes y crear nuevos centros para así alcanzar la universalidad del acceso a los servicios. No obstante, por ejemplo en Chile, ello no funcionó. Los médicos se retiraron de sus centros de trabajo para buscar otros donde sus servicios valgan más, dando como resultado que a ellos acudan, en su mayoría, personas de mayores recursos. Esto produjo un aumento en las brechas de acceso a los servicios contradiciendo la finalidad de la reforma; esto continúa actualmente en dicho país ${ }^{(3)}$. Además, no es certe- ro que por invertir más la reforma sea efectiva; se necesita buenas prácticas, personal capacitado y evidencia científica que demuestre la utilidad de dichas medidas en nuestra realidad ${ }^{(4)}$.

A 30 años de aplicada la reforma de salud en Argentina, Colombia y Chile, el objetivo de equidad universal en los servicios están lejos de ser una realidad. Ya que Latinoamérica tiene raíces y características similares, la mayoría países en desarrollo, no es ajeno pensar en el fracaso de esta en el Perú. No solo por el fallo de la misma en los otros países, sino también porque es usada sin considerar la realidad de cada uno ${ }^{(5)}$. Una reforma de salud es compleja. El objetivo de esta carta no es hacer una revisión de ello, por lo que solo hemos detallado algunos puntos claves que consideramos importantes.

Finalmente, es importante estudiar y analizar más a fondo la realidad del Perú, para poder aplicar la reforma de salud de acuerdo a nuestro contexto específico; aprendiendo de los errores de los otros países, además de basarnos en la evidencia, y seguimiento de los mismos ${ }^{(6)}$. Si consideramos todo ello, quizá pueda decirse en un futuro que logramos las metas de una adecuada reforma de salud. Y es que si nosotros, los futuros médicos del país, nos concientizamos de cómo es nuestra realidad y cómo se transformará con la reforma, podremos participar dando un mayor beneficio a la población. 


\section{REFERENCIAS BIBLIOGRÁFICAS}

1. Gérvas J, Pérez Fernández M. El fundamento científico de la función de filtro del médico general. Rev Bras Epidemiol. 2005;8:2005-17.

2. Gérvas J, Pérez M. Atención primaria fuerte: fundamento clínico, epidemiológico y social en los países desarrollados y en desarrollo. Rev Bras Epidemiol. 2006;9:384-400.

3. Labra ME. Las políticas de salud en Chile y en Brasil. Apuntes para una comparación. Rev Ciencias Sociales.2000;6(2):259-74.

4. Solari L. Reforma de Salud en el Perú: apuntando hacia la cobertura universal. Rev Per Med Exp Salud Publica. 2014;31(4):623-5
5. World Health Organization. Health research is essential for progress towards universal health coverage. [Internet] Ginebra: WHO; c2014. Acceso el 2015 Enero 08. Disponible en: http://www.who. int/mediacentre/news/releases/2013/world_health_ report_20130815/en/.

6. World Health Organization. Health financing for universal coverage. [Internet] Ginebra: WHO; c2014. Acceso el 2015 Enero 08. Disponible en: http://www. who.int/health_financing/countries/en/.

Carta al Editor recibida para publicación el 6 de febrero de 2015.
Conflicto de intereses:

Los autores declaran no tener conflicto de interés.

Fuente de Financiamiento:

El trabajo fue financiado por los propios investigadores.

Datos del autor corresponsal:

Giancarlo François Castillo Tarrillo

Sociedad Científica de San Fernando

Dirección: Mz. C lote 14 Urb Virgen de las Nieves-

San Martín de Porres, Lima, Perú

Teléfono: 990123392

Correo electrónico: giancarlocastillot@gmail.com 